\title{
Direct embryogenesis from anther culture of hot chilli Capsicum annuum $\mathbf{L}$.
}

\author{
Nguyen Tran Dong Phuong ${ }^{1 *}$ \\ ${ }^{1}$ Ho Chi Minh City Open University, Vietnam \\ *Corresponding author: phuong.ntd@ou.edu.vn
}

ARTICLE INFO

ABSTRACT

DOI: $10.46223 / \mathrm{HCMCOUJS}$. tech.en.11.1.560.2021

Received: June $24^{\text {th }}, 2020$

Revised: December 31 ${ }^{\text {st }}, 2020$

Accepted: January $6^{\text {th }}, 2021$

Keywords:

androgenesis, anther culture, culture media direct embryogenesis, haploid, hot chilli
In Viet Nam, local varieties of chilli have a distinctive aroma and pungency. However, the generation of pure lines from pollen culture in local hot chilli has been very limited reported. Therefore, this study was to relate flower bud size with microspore developmental stages and the culture media have concentration changed of plant growth regulator effects on the in vitro androgenesis. Flower buds were randomly collected and visually divided into three stage based on both petal and sepal size. Then, the anthers were cultured on MS basal medium with different concentration of NAA $(0.1-0.7 \mathrm{mg} / \mathrm{L})$, kinetin $(1.0-3.0 \mathrm{mg} / \mathrm{L})$, and BA $(0.5-1.5 \mathrm{mg} / \mathrm{L})$. The results showed that anthers with light violet, $2.5 \mathrm{~mm}$ long, consisted of anthers with $80 \%$ haploid and $20 \%$ dihaploid microspores in the first mitosis were selected. In induction culture media, it was observed that MS medium with $2.0 \mathrm{mg} / \mathrm{L}$ Kinetin and $0.5 \mathrm{mg} / \mathrm{L}$ NAA gave embryos at higher frequencies. MS medium with $1 \mathrm{mg} / \mathrm{L} \mathrm{BA}$ is the best medium for embryo germination and inducting shoots. And $1 / 2$ MS medium adapt for shoot elongation and rooting.

\section{Introduction}

Chilli pepper (Capsicum annum L.) which belongs to the Capsicum genus of Solanaceae family. Which are domesticated species originated from American tropics and was introduced to Viet Nam by the French. Now, chilli is used a lot in the world cuisine. In Viet Nam, local chili varieties have a distinctive aroma and pungency but color and the size of the chili not likely. Therefore, biotechnology is used to improve the quality of chilli.

Dihaploid is a technology to lessen the process of generating new germplasm and reducing the process from 6 generations or more by the classical method down to 2 - 3 generations. The production of such dihaploid plants via androgenesis is a powerful technique for excellent material for plant breeding.

Economically, chilli is an important vegetable crop and pollen embryogenesis through androgenesis was first published in India 1973. Several protocols in microspore induced embryogenesis have been reported in different genotypes (Arjunappa, Kumar, \& Latha, 2016; Rodeva, Irikova, \& Todorova, 2011) or culture medium (Vaulx, Chambonnet, \& Pochard, 1981).

However, there is no specific study on local chilli varieties in Vietnam so microspore stage and the culture medium is not well understood. The aim of this study was to develop a culture medium for the production of double haploids from local chilli varieties in Vietnam which provides an opportunity to shorten the breeding cycle and fix agronomic traits. 


\section{Material and methods}

\subsection{Plant material}

The mother plants for the collection of flower buds were planted in a garden at Ho Chi Minh City Open University, Binh Duong province. Flower buds were randomly collected and visually divided into three classes based on both petal and sepal size to relate flower bud size with microspore developmental stages. First, 6-8-week flower buds were harvested for about at their early flower production period for pollen culture. Second, flower buds were refrigerated at $5 \pm 2$ ${ }^{\circ} \mathrm{C}$ for 2 days to induce cold stress to the anther.

\subsection{Sterilization and anther extraction methods}

The flower buds after fresh and cold treated were initially washed with sterile distilled water. Then these were treated with $70 \%$ ethanol for 3 minutes and then with $10 \%$ sodium hypochlorite for 15 minutes and rinsed in sterile distilled water 3 times.

Then these buds were carefully dissected and individual anthers were separated and placed horizontally on the medium such that the anther was in contact with the medium.

\subsection{Microspore stage}

Anther containing microspores mainly at the late haploid and early dihaploid microspores stage were selected. At this stage, the calyx was shorter than the corolla. The stage of the microspores was observed accurately in acetocarmine stain. The cell was analyzed under a microscope with 100X magnitude.

\subsection{Culture medium}

Anther were cultured on MS basal medium with different concentration of hormones NAA (0.1 - $0.7 \mathrm{mg} / \mathrm{L})$, kinetin (1.0 - 3.0 mg/L), and BA (0.5 1.0 1.5 mg/L). And 1/2 MS medium for shoot elongation and rooting with $30 \mathrm{~g} / \mathrm{L}$ sucrose and $8 \mathrm{~g} / \mathrm{L}$ agar, $\mathrm{pH}$ of the medium 5.7 - 5.8.

\subsection{Culture conditions}

The culture MS supplied with NAA and kinetin were incubated in dark for 2 weeks at 25 ${ }^{\circ} \mathrm{C}$, with $12 \mathrm{~h}$ photoperiod to induce direct embryogenesis. When the embryos appeared as small white protuberances, they were transferred to MS medium with BA and were kept at $25{ }^{\circ} \mathrm{C}$ with $12 \mathrm{~h}$ photoperiod. After 2 months, the plantlets from germinated embryo were transferred to $1 / 2 \mathrm{MS}$ medium add $0.5 \mathrm{~g} / \mathrm{L}$ activated carbon for the shoot and root elongation.

\subsection{Data analysis}

All experiments were arranged in completely randomized block. Comparisons of means were performed by one-way ANOVA (analysis of variance) followed by Duncan test ( $\mathrm{p}$-value < $0.05)$.

\section{Results}

\subsection{Observed morphology and microspore stage}

Flower buds, anther morphology and development stages of chilli microspores: stage of development the flower buds collected were divided into three different stages ( $1 \mathrm{a}, 1 \mathrm{~b} \& 1 \mathrm{c})$. Color of the anthers is viewed as good indicators of the stage of microspore development (2a, $2 \mathrm{~b} \& 2 \mathrm{c})$. Stages of microspore development in anthers were determined using microscope, (3a, 3b \& $3 \mathrm{c})$. Stage-1 flower buds consisted of anthers with haploid microspores (1a - c); stage-2 flower buds consisted of anthers with $80 \%$ haploid and $20 \%$ dihaploid microspores $(2 \mathrm{a}-\mathrm{c})$, and stage- 3 flower buds consisted with mature pollen grains $(3 a-c)$. 

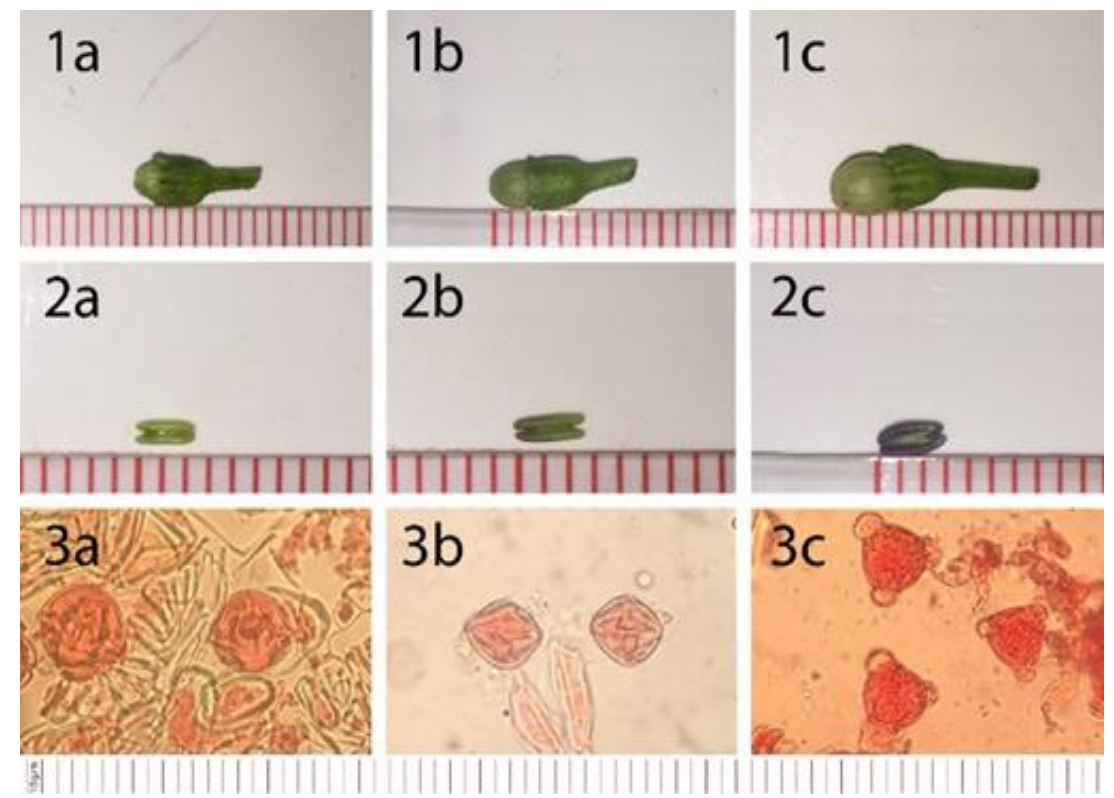

Figure 1. Anther morphology and microspore developmental stage

Note: 1a: Flower buds 3 days before hatch $1.5 \mathrm{~mm}$ petal length.

2a: Anther 3 days before hatching green length of $2.2 \mathrm{~mm}$.

3a: Anther with haploid microspores.

$1 \mathrm{~b}$ : Flower buds 2 days before hatch $2.0 \mathrm{~mm}$ petal length.

$2 \mathrm{~b}$ : Anther 2 days before hatching green length of $2.5 \mathrm{~mm}$.

3b: Anthers with $80 \%$ haploid and $20 \%$ dihaploid microspores.

1c: Flower buds 1 days before hatch $3.0 \mathrm{~mm}$ petal length.

2c: Anther 1 days before hatching green length of $3.0 \mathrm{~mm}$.

3c: Anthers with pollen grains.

\subsection{Effect of concentration of phytohormone NAA on direct embryogenesis}

\section{Table 1}

The number induction anther and shape of anther on MS supplemented with NAA at different concentrations after 14 days

Concentration (MS add NAA (mg/L))

The number induction anthers

\begin{tabular}{cc}
\hline 0.0 & $0.0^{\mathrm{d}}$ \\
\hline 0.1 & $1.67^{\mathrm{c}}$ \\
\hline 0.3 & $3.33^{\mathrm{b}}$ \\
\hline $\mathbf{0 . 5}$ & $\mathbf{6 . 0}^{\mathrm{a}}$ \\
\hline 0.7 & $2.33^{\mathrm{bc}}$ \\
\hline
\end{tabular}

Source: Data analysis result of the research 
The concentration of NAA give the number induction anther highest is MS add NAA 0.5 $\mathrm{mg} / \mathrm{L}, 6$ anthers appear as small white protuberances and lowest is MS add NAA $0.0 \mathrm{mg} / \mathrm{L}$.

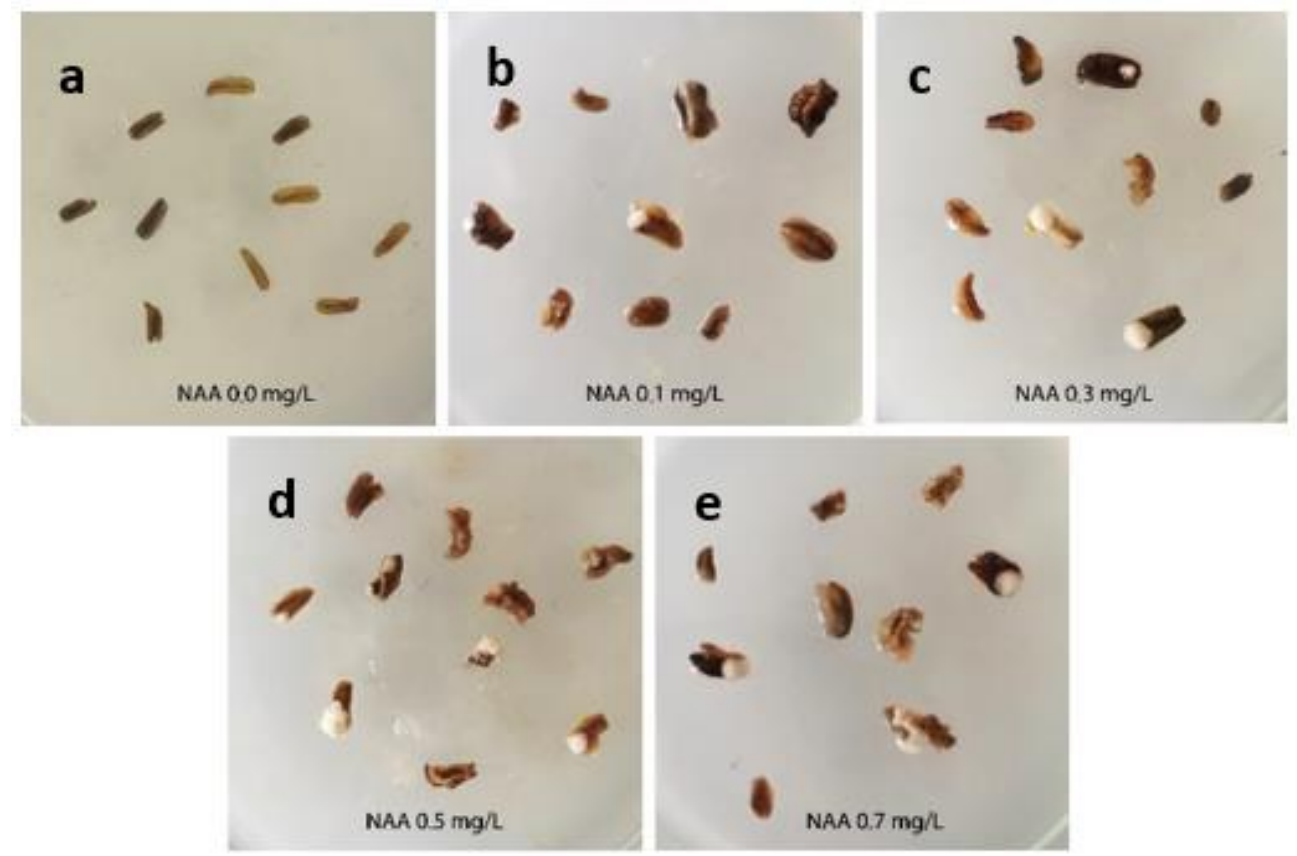

Figure 2. Anthers were cultured on MS basal medium with differences concentration after 14 days

Note: a: The shape of anther not changed, not appear as small white protuberances.

b: The shape of anther little changed, little anther started to appear as small white protuberances.

c: The shape of anther much changed, many anthers appear as small white protuberances.

$\mathrm{d}$ : The shape of anther changed too much, most of anther appear as small white protuberances.

e: The shape of anther little changed, little anther started to appear as small white protuberances.

\subsection{Effect of concentration of hormone kinetin on direct embryogenesis}

MS medium with NAA $0.5 \mathrm{mg} / \mathrm{L}$ was add and kinetin with differences concentration.

\section{Table 2}

The number induction anther and shape of anther on MS medium add NAA $0.5 \mathrm{mg} / \mathrm{L}$ and kinetin with differences concentration after 14 days

\begin{tabular}{cc}
$\begin{array}{c}\text { Concentration (MS add NAA } 0.5 \mathrm{mg} / \mathrm{L} \text { and } \\
\text { kinetin }(\mathbf{m g} / \mathbf{L}))\end{array}$ & The number induction anthers \\
\hline 0.0 & $0.0^{\mathrm{d}}$ \\
\hline 1.0 & $3.33^{\mathrm{c}}$ \\
\hline 1.5 & $5.33^{\mathrm{b}}$ \\
\hline $\mathbf{2 . 0}$ & $\mathbf{8 . 6 7}^{\mathrm{a}}$ \\
\hline 2.5 & $5.67^{\mathrm{b}}$ \\
\hline 3.0 & $2.67^{\mathrm{c}}$ \\
\hline
\end{tabular}

Source: Data analysis result of the research 
The concentration of kinetin gave the number induction anther highest is MS add NAA 0.5 $\mathrm{mg} / \mathrm{L}$ and kinetin $2.0 \mathrm{mg} / \mathrm{L}$ about 8 anthers appear as small white protuberances and lowest is MS add kinetin $0.0 \mathrm{mg} / \mathrm{L}$.

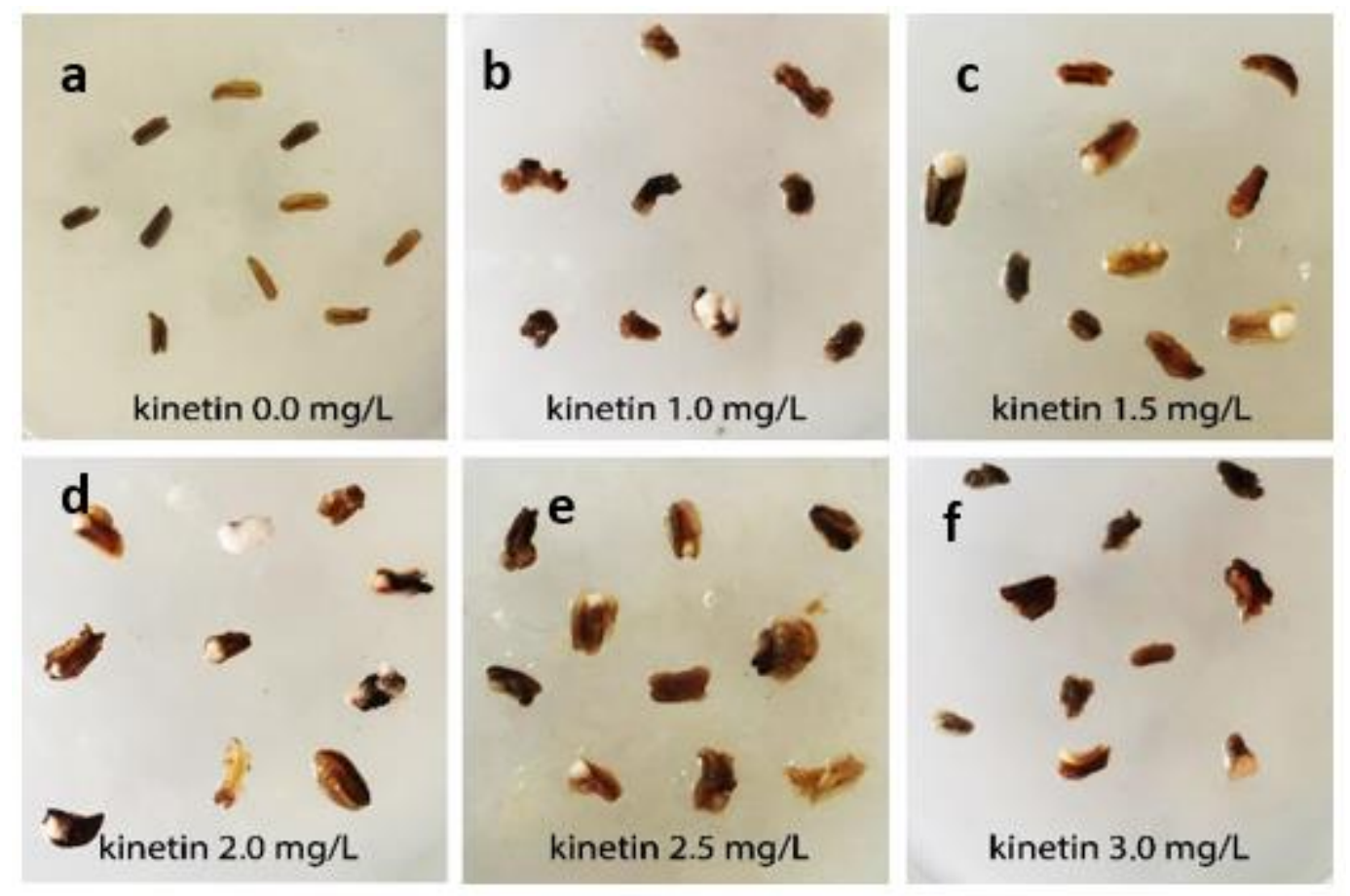

Figure 3. Anthers were cultured on MS basal medium with NAA $0.5 \mathrm{mg} / \mathrm{L}$ and kinetin with differences concentration after 14 days

Note: a: The shape of anther not changed, not appear as small white protuberances.

b: The shape of anther little changed, little anther started to appear as small white protuberances.

c: The shape of anther much changed, many anthers appear as small white protuberances.

$\mathrm{d}$ : The shape of anther much changed, many anthers appear as small white protuberances.

e: The shape of anther little changed, little anther started to appear as small white protuberances.

\subsection{Effect of concentration of hormone BA for embryo germination and creating shoots}

Table 3

The number shoots and shape of shoots on MS medium with BA differences concentration after 8 weeks.

Concentration (MS add BA (mg/L))

The number shoots

\begin{tabular}{ll}
\hline 0.0 & $0.0^{\mathrm{c}}$ \\
\hline 0.5 & $1.0^{\mathrm{b}}$ \\
\hline $\mathbf{1 . 0}$ & $\mathbf{3 . 3 3}^{\mathrm{a}}$ \\
\hline 1.5 & $0.33^{\mathrm{bc}}$ \\
\hline
\end{tabular}

Source: Data analysis result of the research

The concentration BA give the number shoots highest is MS add BA $1.0 \mathrm{mg} / \mathrm{L}$ about 3 shoots were created and lowest is MS add BA $0.0 \mathrm{mg} / \mathrm{L}$. 

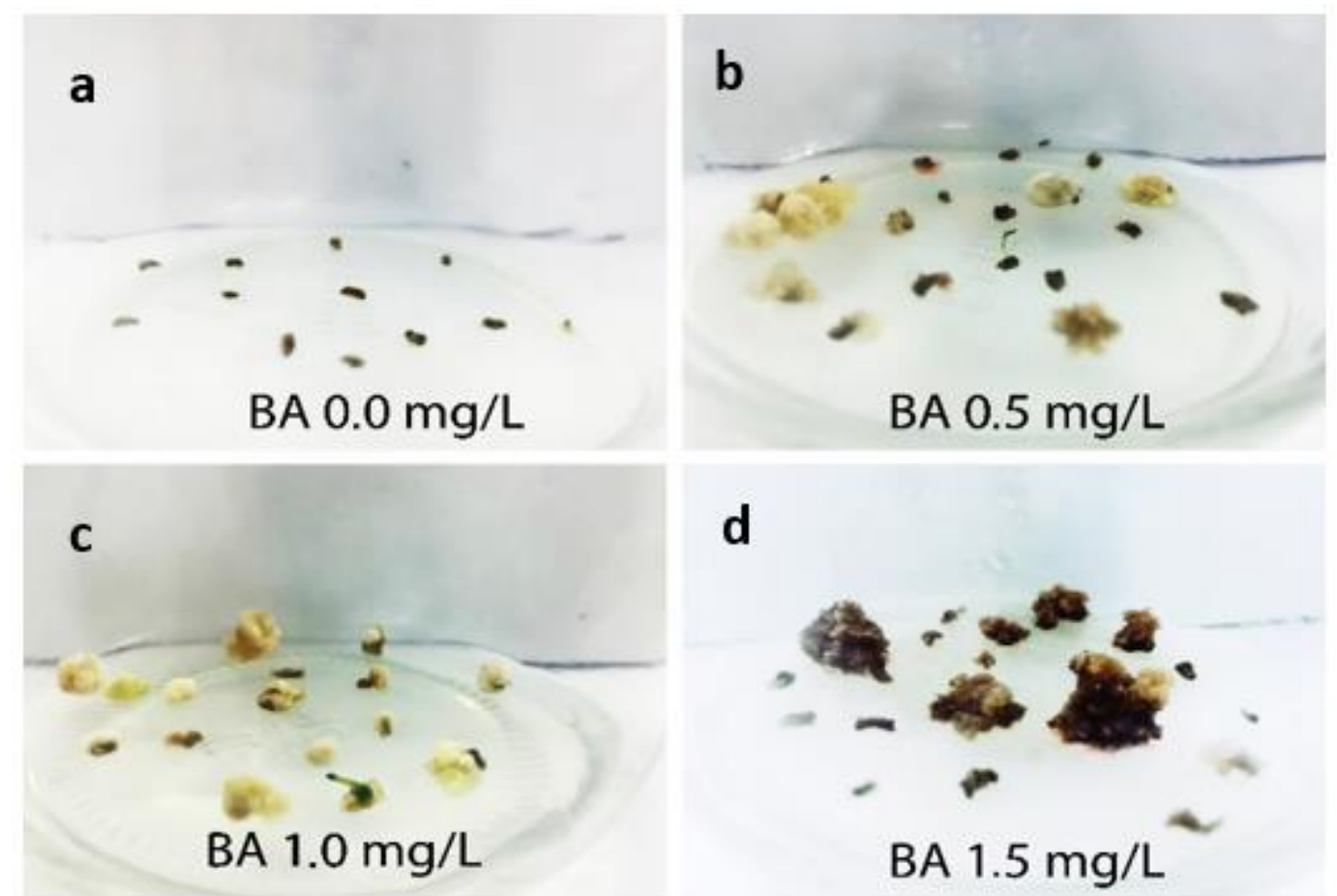

Figure 4. Embryos were cultured on MS basal medium with BA at differences concentration after 8 weeks.

Note: a: The embryo does not grow

b: The embryo germination, shoots have one cotyledon.

c: The embryo germination, shoots have two cotyledons

d: Callus was created.

After 2 months the embryo germinated plants were transferred to $1 / 2$ MS medium add 0.5 $\mathrm{g} / \mathrm{L}$ activated carbon for the shoot and root elongation.

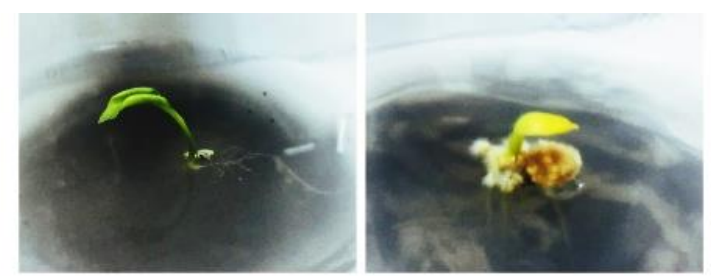

BA $0.5 \mathrm{mg} / \mathrm{L}$
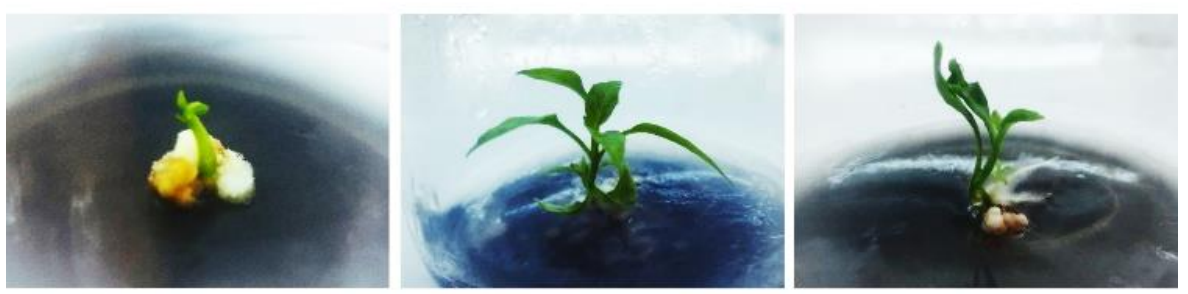

BA $1.0 \mathrm{mg} / \mathrm{L}$

Figure 5. Shoots were transferred to $1 / 2 \mathrm{MS}$ medium add $0.5 \mathrm{~g} / \mathrm{L}$ activated carbon after few days.

After 4 weeks cultured, chilli leaves are $6-8$ and $6 \mathrm{~cm}$ high. Then they were transferred to the greenhouse. 


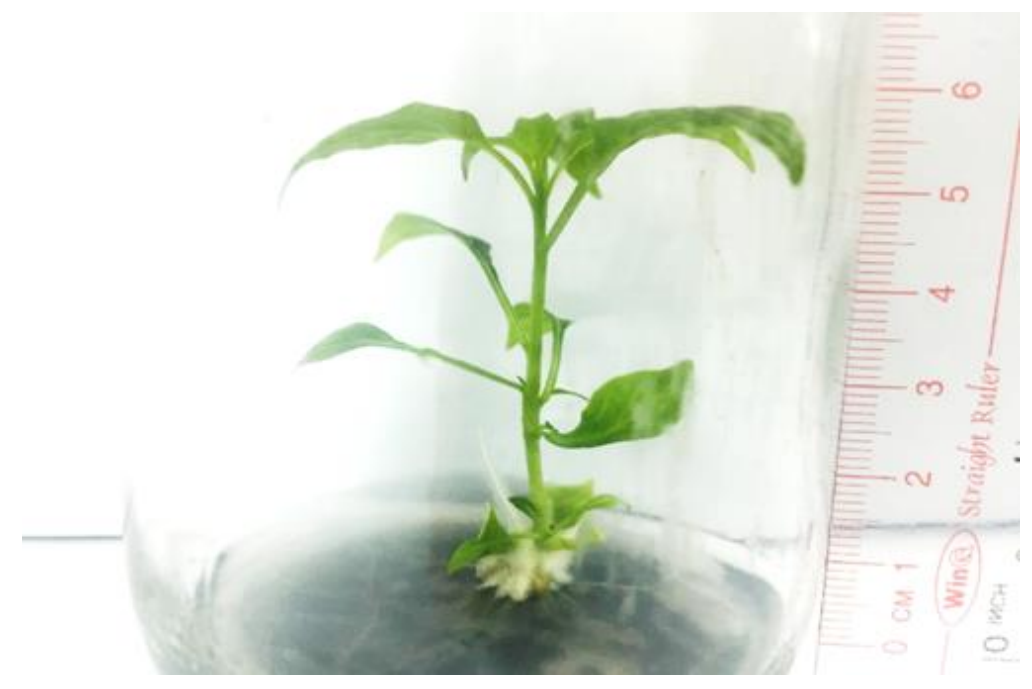

Figure 6. Chilli after 4 weeks cultured

\section{Discussions}

In this study bud flower have anthers are light violet in color, $2.5 \mathrm{~mm}$ long, consisted of anthers with $80 \%$ haploid and $20 \%$ dihaploid microspores were selected. Microspores in the process of first pollen mitosis occur in flower buds with corolla petals and calyx sepals of equal length or with petals slightly longer than sepals (Nowaczyk \& Kisiala, 2006). Anthers containing $80 \%$ haploid and 20\% dihaploid microspores yielded the highest frequency of successful microspore cultures (Lantos et al., 2012).

The type of media and concentration of plant growth regulators are crucial factors for determining embryogenesis in anther culture of capsicum (Ciner \& Tipirdamaz, 2002). Each concentration of hormones showed different embryogenesis response in different media. The results showed that NAA concentrations affected the anther induction, however, in this study, the number of anther induction is lower than MS basal with NAA at $0.5 \mathrm{mg} / \mathrm{L}$ and kinetin at $1.0 \mathrm{mg} / \mathrm{l}$ studied by Yang et al. (2009). Therefore, use the best concentration of NAA combine with kinetin at different concentrations to find the best anther culture medium. The combinations of NAA 0.5 $\mathrm{mg} / \mathrm{L}$ and kinetin $2.0 \mathrm{mg} / \mathrm{L}$ is the best culture medium, high-frequency induction anther $(86,7 \%)$. The BA concentrations effected for embryo germination, the concentration of BA at $1.0 \mathrm{mg} / \mathrm{L}$ gave the highest embryogenesis of $33.3 \%$.

\section{Conclusion}

From our study, we have found that stage of the microspores and media culture important role in direct embryogenesis in chilli. Anthers with light violet in color, $2.5 \mathrm{~mm}$ long, consisted of anthers with $80 \%$ haploid and $20 \%$ dihaploid microspores were better for embryogenesis than anthers in other stages. Different types of growth regulators and their varied concentrations in the MS media played an important role such as highest embryo frequency was observed in MS medium with $2.0 \mathrm{mg} / \mathrm{L}$ Kinetin and $0.5 \mathrm{mg} / \mathrm{L}$ NAA and lowest embryo frequency in MS without hormones. The concentration of BA at $1.0 \mathrm{mg} / \mathrm{L}$ gave the highest embryogenesis of $33.3 \%$.

\section{References}

Arjunappa, H. M., Kumar, S., \& Latha, P. (2016). Effect of genotype and media on direct embryogenesis of chilli pepper (Capsicum annuum L.). International Journal of Recent Scientific Research, 7(1), 8592-8595. 
Ciner, D. O., \& Tipirdamaz, R. (2002). The effects of cold treatment and charcoal on the in vitro androgenesis of pepper (Capsicum annuum L.). Turkish Journal of Botany, 26, 131-139.

Lantos, C., Juhasz, A. G., Vagi, P., Mihaly, R., Kristof, Z., \& Paul, J. (2012). Androgenesis induction in microspore culture of sweet pepper (Capsicum annuum L.). Plant Biotechnology Reports, 6, 123-132.

Nowaczyk, P., \& Kisiala, A. (2006). Effect of selected factors on the effectiveness of Capsicum annuum L. anther culture. Journal of Applied Genetics, 47(2), 113-117.

Rodeva, V. N., Irikova, T. P., \& Todorova, V. J. (2011). Anther culture of pepper (Capsicum Annuum L.): Comparative study on effect of the genotype. Biotechnology \& Biotechnological Equipment, 18(3), 34-38.

Vaulx, D. R., Chambonnet, D., \& Pochard, E. (1981). In vitro culture of pepper (Capsicum annuum L.) anthers: High rate plant production from different genotypes by $+35^{\circ} \mathrm{C}$ treatments. Agronomie, 1, 859-864.

Yang, B. Z., Zhou, S. D., Zhang, Z. Q., Dai, X. Z., Li, L. H., \& Xie, D. P. (2009). Effects of different medium and hormone on cultured anther of hot pepper. Journal of Hunan Agricultural University, 35(1), 61-64. 